\title{
Effects of Group Cognitive-Behavioral Therapy in Young Patients in the Early Stage of Psychosis
}

\author{
Sung-Wan Kim ${ }^{1,2}$, Ji-Eun Jang ${ }^{1}$, Ju-Yeon Lee ${ }^{1,2}$, Ga-Young Lee ${ }^{1}$, Hye-Young Yu ${ }^{1}$, \\ Cheol Park', Hee-Ju Kang ${ }^{2}$, Jae-Min Kim², and Jin-Sang Yoon ${ }^{2}$ \\ ${ }^{1}$ Mindlink, Gwangju Bukgu Community Mental Health Center, Gwangju, Republic of Korea \\ 2Department of Psychiatry, Chonnam National University Medical School, Gwangju, Republic of Korea \\ ${ }^{3}$ Department of Psychiatry, Gwangju Veterans Hospital, Gwangju, Republic of Korea
}

Objective To develop a model of group cognitive-behavioral therapy (CBT) for Korean patients with early psychosis.

Methods The group CBT utilized in the present study consisted of metacognitive training, cognitive restructuring, and lifestyle managements. The Subjective Well-being Under Neuroleptics (SWN-K), Ambiguous Intentions Hostility Questionnaire (AIHQ), Drug Attitude Inventory (DAI), Beck Depression Inventory (BDI), Perceived Stress Scale (PSS), and Clinical Global Impression (CGI) were administered prior to and after CBT sessions. The participants were categorized into two groups according to the median duration of untreated psychosis (DUP; 4 months).

Results A total of 34 patients were included in this analysis. From pre- to post-therapy, there were significant increases in the SWN-K and DAI scores and significant decreases in the hostility subscale of the AIHQ, PSS, and CGI scores. Significant time $\times$ DUP interaction effects were observed for the SWN-K, DAI, and BDI scores, such that there were significant changes in patients with a short DUP but not in those with a long DUP.

Conclusion The group CBT program had a positive effect on subjective wellbeing, attitude toward treatment, perceived stress, and suspiciousness of young Korean patients with early psychosis. These effects were particularly significant in patients with a short DUP.

Psychiatry Investig 2017;14(5):609-617

Key Words Schizophrenia, Early psychosis, Cognitive-behavioral therapy, Group therapy, Duration of untreated psychosis.

\section{INTRODUCTION}

The intent of early intervention procedures for patients with schizophrenia is to provide effective treatment during the early stages of the disorder to reduce its ultimate severity., ${ }^{1,2}$ The primary method of early intervention involves shortening the duration of untreated psychosis (DUP), which is defined as the period from the onset of psychosis to the onset of antipsychotic treatment. ${ }^{3}$ After controlling for relevant confounding variables, a longer DUP was found to be associated with a lower rate of remission of positive symptoms, worse

Received: August 28, 2016 Revised: October 13, 2016

Accepted: November 7, 2016 Available online: July 7, 2017

$\triangle$ Correspondence: Jin-Sang Yoon, MD, PhD

Department of Psychiatry, Chonnam National University Medical School, 160 Baekseo-ro, Dong-gu, Gwangju 61469, Republic of Korea

Tel: +82-62-220-6142, Fax: +82-62-225-2351, E-mail: jsyoon@chonnam.ac.kr

(a) This is an Open Access article distributed under the terms of the Creative Commons Attribution Non-Commercial License (http://creativecommons.org/licenses/bync/4.0) which permits unrestricted non-commercial use, distribution, and reproduction in any medium, provided the original work is properly cited. global functioning, and a poorer quality of life at follow-up.-8 Therefore, the DUP represents a modifiable predictor of outcomes during the early course of schizophrenia. ${ }^{9}$ A secondary method of early intervention involves intensive treatment during the critical period of schizophrenia, i.e., the first 3-5 years, because the future course and prognosis of patients are determined during this period. ${ }^{10,11}$

The guideline of the National Institute for Health and Care Excellence (NICE) in the UK recommends that early interventions provided by psychosis services should be accessible to all individuals with a first episode or first presentation of psychosis, irrespective of that individual's age or DUP. ${ }^{12}$ Furthermore, these early interventions should provide a full range of pharmacological, psychological, social, occupational, and educational interventions. A key element of the psychological interventions for individuals with first-episode psychosis is cognitive-behavioral therapy, ${ }^{12,13}$ the efficacy of which has been well established. ${ }^{14-17}$ The components of cognitive-behavioral therapy (CBT) for patients with psychosis should in- 
clude the establishment of a relationship between the patient's thoughts, feelings, and actions and their symptoms and functioning, as well as the monitoring of their thoughts, feelings, and behaviors with respect to their symptoms. ${ }^{12,14}$ Additionally, CBT should promote alternative ways of coping with the target symptoms and reducing the distress associated with the disorder. $^{12}$

Although many studies have investigated the effects of CBT in patients with psychosis, a majority of these studies have focused on individualized CBT interventions rather than group interventions. ${ }^{18}$ Recently, group therapies that treat cognitive biases have been applied to patients with psychotic disorders. ${ }^{18-20}$ One example is group metacognitive training (MCT), ${ }^{21,22}$ which have been reported to effectively improve delusional symptoms, self-esteem, and well-being in patients with schizophrenia. ${ }^{23,24}$

Although active clinical and psychosocial services, including CBT, are typically provided to patients with psychosis from the early stage of illness in Western countries, ${ }^{14}$ services and research in this area are not yet well developed or actively reported in Asian countries. Thus, the present study aimed to develop a model of group CBT for Korean patients with early psychosis and to evaluate the effectiveness of this model.

\section{METHODS}

\section{Development of the group CBT program}

Gwangju Bukgu-Community Mental Health Center (CMHC) initiated a program that includes early intervention services for young people with psychosis, as part of a national demonstration project exhibiting special community mental health services in Korea. Clinical and research teams at Gwangju Bukgu-CMHC and Chonnam National University Hospital

Table 1. Contents of the group cognitive behavioral therapy program

\begin{tabular}{lrl}
\hline \multicolumn{1}{c}{ Category } & Session & \multicolumn{1}{c}{ Theme } \\
\hline Introduction & 1 & Introduction and pre-evaluation \\
Meta-cognitive & 2 & Attribution style \\
training & 3 & Jumping to conclusion 1 \\
& 4 & Jumping to conclusion 2 \\
& 5 & Theory of mind \\
& 6 & Memory \\
Cognitive & 7 & Automatic thought \\
restructuring & 8 & Cognitive distortion \\
& 9 & Alternative and reasonable thinking \\
Lifestyle & 10 & Knowing and overcoming hallucination \\
management & 11 & Enhancing self-esteem \\
& 12 & Stress management \\
& 13 & Setting goals and time management \\
Summary & 14 & Summary, sharing, and post-evaluation \\
\hline
\end{tabular}

launched a 13 session group CBT program in August 2012 and then revised it to include 14 sessions in 2014 (Table 1); this CBT program consists of three components: MCT, cognitive restructuring, and stress management. First, five sessions of the MCT procedure, which was developed at the University Medical Center Hamburg-Eppendorf, were selected and modified for the present study. ${ }^{21}$ The MCT is a manualized group treatment program that targets dysfunctional coping styles and cognitive biases involved in the formation and maintenance of psychotic symptoms such as attributional distortions, jumping to conclusions, and impaired social cognition. ${ }^{21,22}$ After these were implemented, three sessions of cognitive restructuring using Beck's cognitive therapy model were conducted, ${ }^{25}$ and then three or four lifestyle management sessions that included stress management, self-esteem enhancement and the process of setting goals were conducted. ${ }^{21,26}$ The first and last sessions were used for introduction and summary purposes, respectively, as well as evaluations and feedback. In addition to the many pictures used during MCT, approximately 10 Korean drama or comedy clips were used to practice cognitive therapy.

\section{Subjects and measures}

The participants in the present study were young Korean individuals who utilized the early intervention services, including group CBT, of Gwangju Bukgu-CMHC; these services are provided to people between 15 and 35 years of age. ${ }^{27,28}$ Most patients who received the early intervention service had a psychotic disorder lasting less than 5 years.

The present study was a retrospective chart review study. For inclusion in this study, the patients were required to be 15-35 years of age, have a diagnosis of a psychotic disorder or psychotic features according to the criteria of the Diagnostic and Statistical Manual of Mental Disorders, fifth edition, ${ }^{29}$ have completed more than $70 \%$ of the sessions, and have completed all scales before and after the CBT sessions. This study was approved by the Institutional Review Board of Chonnam National University Hospital.

\section{Measures}

Demographic and clinical information, including age, gender, education, duration of illness, diagnosis, history of psychiatric admission, history of suicide attempts, chlorpromazine equivalent dosage of antipsychotics, and DUP, were collected from the clinical records at Gwangju Bukgu-CMHC. Self-reports were routinely obtained during the first and final sessions to collect feedback from the participants. These reports included the Subjective Well-being Under Neuroleptics short form (SWN-K) scale for subjective quality of life, ${ }^{30,31}$ Ambiguous Intentions Hostility Questionnaire (AIHQ) for hostile so- 
cial cognitive biases and paranoia, ${ }^{32,33}$ Drug Attitude Inventory (DAI) for attitude toward treatment, ${ }^{34,35}$ Beck Depression Inventory (BDI) for depression, ${ }^{36,37}$ and Perceived Stress Scale (PSS) for stress levels. ${ }^{38,39}$ General severity was determined using the Clinical Global Impression (CGI), which was performed by the case managers. ${ }^{40}$

The AIHQ is a self-report scale comprised of 15 hypothetical negative situations that vary in intentionality (ambiguous, intentional, and accidental situations). ${ }^{41}$ This study used the five questions involving ambiguous situations. ${ }^{42}$ The AIHQ yields Hostility and Aggression bias scores and a composite Blame bias score. The perceived Hostility and Aggression bias scores are calculated by objective ratings of the participant's written responses. The composite Blame score is the mean score of the subject's ratings of intent, anger, and blame. ${ }^{43}$ A greater tendency toward perceived hostility with the AIHQ is a significant predictor of the degree of persecution or paranoia in patients with schizophrenia. ${ }^{41,43}$ The SWN-K, which is the most widely used self-report scale for assessing the well-being of patients, includes 20 items that are rated on a 6-point Likert scale. The SWN-K measures five domains: emotional regulation, mental functioning, self-control, social integration, and physical functioning. Higher scores on the SWN-K and DAI indicate better status and higher AIHQ, BDI, PSS, and CGI scores indicate worse clinical status.

The DUP was assessed by a clinical interview. Due to the lack of standardized criteria available to distinguish between a short and long DUP, the median split approach was selected to maximize statistical power and to optimize the interpretation of the findings. ${ }^{3,43}$

\section{Statistical analysis}

The participants were categorized into two groups according to the median value of DUP. The sociodemographic and clinical variables of the two groups were compared using the chi-square test, independent t-test, or Mann-Whitney U test, as appropriate. Repeated measure analysis of variance (ANOVA) for outcome measures was conducted to evaluate time effects between at baseline and at the endpoint. To evaluate the effects of the DUP as a moderator of treatment effectiveness, a two-way repeated-measure ANOVA with time and DUP representing values below or above the median was conducted after adjusting for gender and baseline scores. The twoway interaction compared the slope of linearized time for patients in the group CBT program who had a DUP either higher or lower than the median. The effect size estimates were determined using the method of Cohen, which was computed as the difference between the endpoint and baseline mean values divided by the standard deviation. ${ }^{44}$ All statistical tests were two-tailed, and a $\mathrm{p}$ value $<0.05$ was considered to indicate statistical significance. The Statistical Package for Social Sciences version 21.0 for Windows (SPSS Inc., Chicago, IL, USA) was used for all statistical analyses.

\section{RESULTS}

The present study initially included 58 patients who participated in the group CBT program between September 2012 and December 2015; each group CBT session included 5-9 patients. Among them, 47 (81.0\%) patients completed more than $70 \%$ of the total sessions and 11 (19.0\%) patients dropped out, mainly due to lack of interests. After excluding patients who did not complete all scales both before and after group CBT $(n=5)$ and who were not diagnosed with a psychotic disorder $(n=8), 34$ patients were included in this analysis. The mean age of the participants was $23.2 \pm 4.7$ years, and the median (interquartile range) duration of illness and DUP were 3.8 years (1.1-6.0) and 4.0 months (1.7-18.2), respectively. Of the participants, 24 (70.6\%) were diagnosed with schizophrenia, seven $(20.6 \%)$ were diagnosed with other specified schizophrenia spectrum disorder, and three $(8.8 \%)$ were diagnosed with affective psychosis. Additionally, 24 (70.6\%) had a history of psychiatric hospitalization, 16 (47.1\%) had a history of suicide attempts, and 26 (76.4\%) patients had CGI scores of 3 (mild) or 4 (moderate), while none had scores higher than 5 (severe).

When the participants were categorized into two groups according to the median DUP (4 months), it was revealed that patients with a DUP $>4$ months were more likely to be female and to have a significantly higher DAI score. No significant differences were observed between the two groups in any of the other clinical characteristics, including scores on the other scales and number of sessions completed (Table 2). Table 3 shows the changes in scores on the scales after group CBT. Significant time effects were observed for the SWN, DAI, the hostility subscale of the AIHQ, PSS, and CGI. The SWN-K and DAI scores exhibited a significant increase from pre- to posttherapy, while scores on the PSS, CGI, and the hostility subscale of the AIHQ decreased significantly. The scores for the mental functioning and physical functioning subscales of the SWN-K also increased significantly. The BDI scores decreased after the CBT sessions, but this change did not reach statistical significance $(\mathrm{p}=0.084)$.

After adjusting for gender and baseline scores, significant time $\times$ DUP interactions were observed for the SWN-K, DAI, and BDI scores (Table 3 ). Figure 1 shows that there were significant changes on these scales in the short DUP group $(\leq 4$ months) but not in the long DUP group ( $>4$ months). The effect sizes for the improvements in these scales were either medium or large in the patients with a short DUP (Cohen's $\mathrm{d}=$ 
0.459-1.052). There were also significant time $\times$ DUP interactions observed for the mental functioning, emotional regulation, and social interaction subscales of the SWN-K (Figure 1), such that patients with a short DUP exhibited significantly increased scores. Scores on the CGI and hostility subscale of the
AIHQ were significantly decreased in both groups, and the effect sizes for the improvements in these scales were medium and large, respectively. There was no relapse, re-hospitalization, or serious adverse event associated with the group CBT.

Table 2. Comparisons of sociodemographic and clinical characteristics according to the median DUP

\begin{tabular}{|c|c|c|c|}
\hline & DUP $\leq 4$ months $(\mathrm{N}=18)$ & DUP $>4$ months $(\mathrm{N}=16)$ & p-value \\
\hline Age, years & $22.6(4.6)$ & $23.9(4.8)$ & 0.395 \\
\hline Gender, female, $\mathrm{N}(\%)$ & $6(33.3)$ & $12(75.0)$ & 0.015 \\
\hline Education, years & $13.4(2.3)$ & $14.2(1.9)$ & 0.273 \\
\hline Duration of illness, years & $3.7(1.0-6.0)$ & $3.9(1.3-4.9)$ & 0.478 \\
\hline DUP, months & $1.9(1.0-3.3)$ & $20.3(12.0-47.1)$ & $<0.001$ \\
\hline Diagnosis of schizophrenia, N (\%) & $12(66.7)$ & $12(75.0)$ & 0.715 \\
\hline History of psychiatric admission, yes (\%) & $13(72.2)$ & $11(68.8)$ & 1.000 \\
\hline History of suicide attempt, yes (\%) & $8(44.4)$ & $8(50.0)$ & 0.746 \\
\hline Antipsychotics dosage, $\mathrm{CPZ}$ equivalent $\mathrm{mg}$ & $250(100-525)$ & $400(125-1200)$ & 0.251 \\
\hline Sessions completed, $\mathrm{N}$ & $11.9(1.1)$ & $11.6(1.4)$ & 0.457 \\
\hline Subjective well-being under neuroleptics & $69.5(21.7)$ & $69.9(14.0)$ & 0.944 \\
\hline AIHQ, Hostility & $2.6(0.6)$ & $2.4(0.7)$ & 0.335 \\
\hline Blame & $2.6(0.6)$ & $2.5(0.6)$ & 0.612 \\
\hline Aggression & $1.6(0.2)$ & $1.5(0.3)$ & 0.557 \\
\hline Perceived Stress Scale & $20.6(8.3)$ & $20.3(5.3)$ & 0.900 \\
\hline Beck Depression Inventory & $12.4(9.8)$ & $12.1(9.6)$ & 0.923 \\
\hline Drug Attitude Inventory & $1.4(3.7)$ & $4.6(3.3)$ & 0.014 \\
\hline Clinical Global Impression & $3.4(0.9)$ & $3.6(0.8)$ & 0.696 \\
\hline
\end{tabular}

Values are mean (standard deviation), number (percentage), or median (interquartile range), as appropriately. AIHQ: Ambiguous Intentions Hostility Questionnaire, DUP: duration of untreated psychosis

Table 3. Changes in scores on the scales after group cognitive behavioral therapy

\begin{tabular}{|c|c|c|c|c|c|c|c|}
\hline & \multicolumn{4}{|c|}{ Total $(\mathrm{N}=34)$} & \multirow{2}{*}{$\begin{array}{c}\text { Time } \times \text { DUP } \\
\text { p-value }^{\dagger}\end{array}$} & \multirow{2}{*}{$\begin{array}{c}\text { DUP } \leq 4 \text { months } \\
(\mathrm{N}=18) \\
\mathrm{ES}(\mathrm{d})\end{array}$} & \multirow{2}{*}{$\begin{array}{c}\text { DUP }>4 \text { months } \\
\quad(\mathrm{N}=16) \\
\mathrm{ES}(\mathrm{d})\end{array}$} \\
\hline & Baseline & Endpoint & p-value & $\mathrm{ES}(\mathrm{d})$ & & & \\
\hline SWN, total & $69.71(18.18)$ & $74.29(18.56)$ & 0.044 & 0.249 & 0.001 & $0.460^{* *}$ & -0.115 \\
\hline Mental functioning & $13.09(4.41)$ & $14.24(4.12)$ & 0.047 & 0.269 & 0.027 & $0.466^{* *}$ & -0.055 \\
\hline Self-control & $14.47(4.30)$ & $15.21(4.40)$ & 0.269 & 0.170 & 0.069 & 0.338 & 0.149 \\
\hline Emotional regulation & $14.65(4.20)$ & $15.24(4.51)$ & 0.373 & 0.135 & 0.001 & 0.406 & -0.261 \\
\hline Physical functioning & $13.47(4.47)$ & $14.76(4.26)$ & 0.034 & 0.295 & 0.287 & 0.283 & 0.318 \\
\hline Social interaction & $14.03(4.46)$ & $14.85(4.41)$ & 0.242 & 0.185 & $<0.001$ & $0.480^{*}$ & -0.337 \\
\hline Drug Attitude Inventory & $2.94(3.85)$ & $5.35(3.58)$ & $<0.001$ & 0.650 & 0.011 & $1.041^{* * *}$ & 0.188 \\
\hline AIHQ, Hostility & $2.46(0.64)$ & $1.89(0.56)$ & $<0.001$ & 0.948 & 0.197 & $1.249^{* * *}$ & $0.682^{* *}$ \\
\hline Blame & $2.58(0.59)$ & $2.43(0.63)$ & 0.231 & 0.246 & 0.471 & 0.374 & 0.073 \\
\hline Aggression & $1.55(0.26)$ & $1.66(0.39)$ & 0.100 & -0.331 & 0.149 & -0.488 & -0.314 \\
\hline Perceived Stress Scale & $20.47(6.96)$ & $17.94(6.68)$ & 0.045 & 0.371 & 0.201 & 0.512 & 0.184 \\
\hline Beck Depression Inventory & $12.24(9.56)$ & $9.76(7.32)$ & 0.084 & 0.291 & 0.013 & $0.652^{*}$ & -0.048 \\
\hline Clinical Global Impression & $3.51(0.85)$ & $3.06(0.85)$ & $<0.001$ & 0.515 & 0.960 & $0.433^{* * *}$ & $0.599^{* * *}$ \\
\hline
\end{tabular}

${ }^{*} \mathrm{p}<0.05,{ }^{* *} \mathrm{p}<0.01,{ }^{* * *} \mathrm{p}<0.001,{ }^{\dagger}$ adjusted for sex and baseline score. ES: effect size, DUP: duration of untreated psychosis, SWN: Subjective Well-being Under Neuroleptics, AIHQ: Ambiguous Intentions Hostility Questionnaire 


\section{DISCUSSION}

The present findings demonstrated that the group CBT program for patients with early psychosis effectively increased subjective well-being and attitude toward treatment and decreased suspiciousness and perceived stress. The improvements in well-being and attitude toward treatment were particularly significant in patients with a DUP that was shorter than 4 months, and the effect sizes were moderate to large, while suspiciousness and global severity improved regardless of the
DUP. To the best of our knowledge, this is the first study to show the beneficial effects of a group CBT program on subjective responses in young Asian patients with early psychosis, and that these effects were mediated by the DUP. In addition, the drop-out rate was not high, and no serious adverse event associated with group CBT was observed. This suggests that group CBT may be an effective and practical therapeutic tool in Korean patients with early psychosis.

The group CBT program used in the present study is composed of three parts. Therapeutic mechanisms and theoreti-
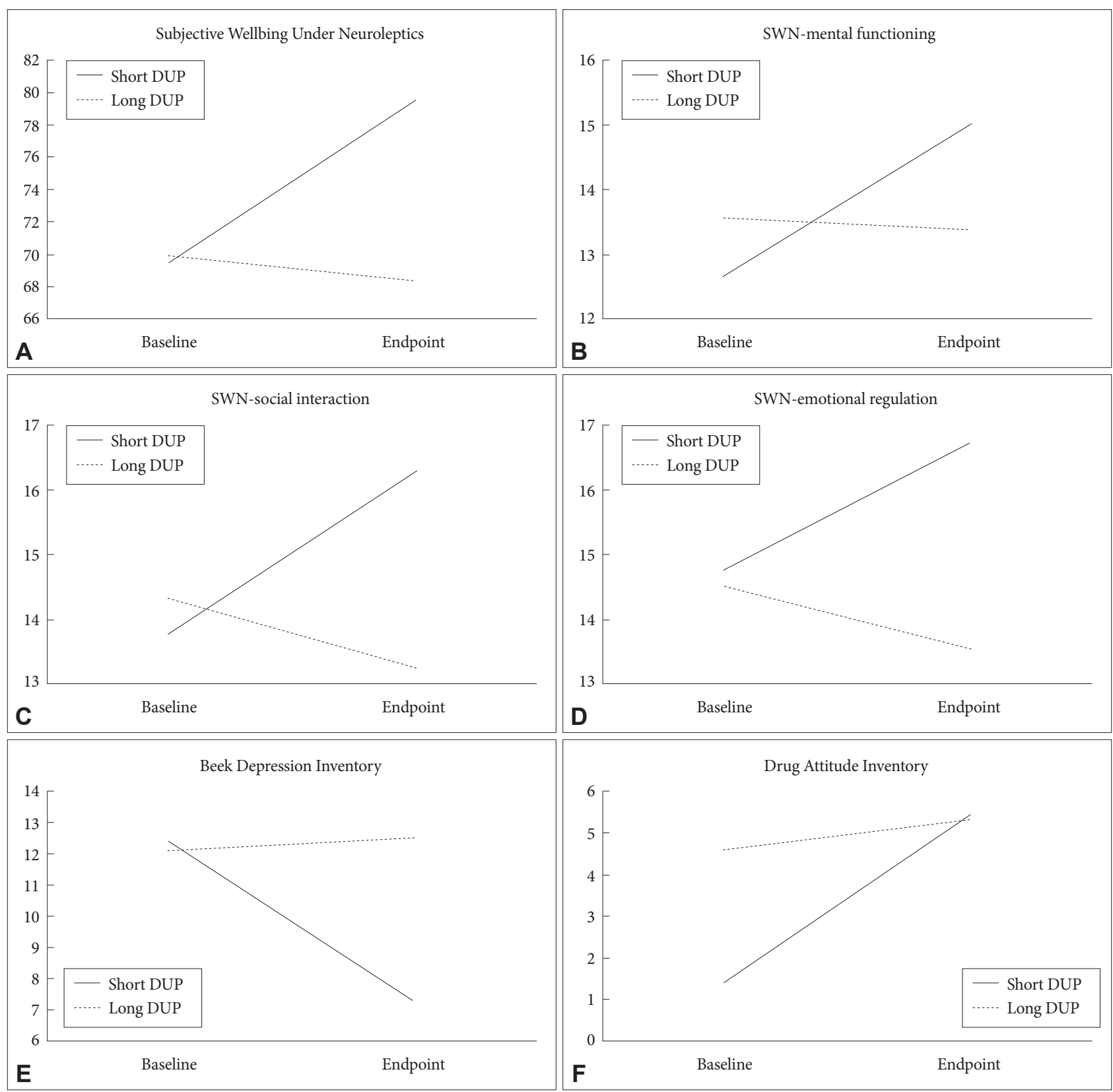

Figure 1. Changes in scores on the scales after group cognitive-behavioral therapy according to the median duration of untreated psychosis (DUP). p-values of paired t-tests in short DUP and long DUP groups are (A) 0.007 and 0.469 , (B) 0.005 and 0.804 , (C) 0.029 and 0.108 , (D) 0.075 and 0.136 , (E) 0.018 and 0.810 , and $(F)<0.001$ and 0.370 , respectively. SWN: Subjective Wellbing Under Neuroleptics. 
cal backgrounds of these three parts are somewhat heterogeneous but are closely associated with each other in this program. The first part, MCT, aims to enhance patient awareness regarding cognitive biases and cognitive flexibility. ${ }^{21}$ Metacognition refers to the general ability to think about thinking, i.e., the ability to think about one's mental state and the mental states of others. ${ }^{45}$ Training programs that improve metacognition, which is impaired in patients with schizophrenia, may help motivate patients to restructure their cognitive distortions. Previous studies investigating insight into an individual's illness and cognitive flexibility, or the ability to consider alternative beliefs, as predictors of better CBT outcomes have supported the potential effectiveness of the combination of MCT and formal cognitive therapy. ${ }^{46-49}$ After learning cognitive restructuring, the patients were encouraged to adopt these skills in real life with subsequent sessions on stress and time management and enhancing self-esteem. This sequential combination of techniques may help patients decrease suspiciousness and perceived stress while increasing their subjective wellbeing and positive attitudes toward treatment.

Group CBT is a cost-effective method to deliver cognitive behavioral therapies, but compared with individual CBT, this technique has recently been developed for and evaluated in patients with psychosis. While previous studies have shown that group CBT and MCT effectively treat psychosis, ${ }^{13,16,23,24}$ there are conflicting results and heterogeneity in terms of the outcome measures. ${ }^{15,18}$ For example, some patients experience significant benefits from participating in group psychotherapy, whereas others achieve only minimal gains. ${ }^{49}$ Alliance with one's therapist, a feeling of cohesion, and conscientiousness are predictors of better group CBT outcomes. ${ }^{20,50}$ The present findings suggest that the DUP is also a predictive factor in the effectiveness of group CBT.

Many previous studies have shown that the DUP influences various aspects of short-term and long-term improvements in the symptoms of patients with first-episode psychosis ${ }^{6,8,51-53}$ Furthermore, meta-analyses investigating the associations between the DUP and long-term outcomes determined that a longer DUP is significantly correlated with a lower likelihood of remission, poor social functioning, and worse global outcomes. ${ }^{3,54,55}$ However, definitive conclusions cannot be made regarding the longitudinal effects of the DUP on employment and quality of life, due to the small number of studies evaluating these issues. ${ }^{55}$ Furthermore, there is a relative lack of evidence showing the influences of the DUP on the effects of specific psychosocial treatments, including CBT, in young patients with psychosis.

The present study findings, showing that there were significant improvements in subjective responses in patients with a short DUP but not a long DUP, support the need for early intervention in psychosis services. ${ }^{1}$ Thus, delays in treatment may reduce the therapeutic potential of psychosocial interventions provided during the course of the illness. Cognitive deficits, which is associated with an extended DUP, ${ }^{56,57}$ may interfere with a patient's ability to engage with existing forms of CBT, because cognitive therapies require patients to utilize memory and problem-solving functions..$^{58}$ In the short DUP group, functional and developmental reserves against the toxic effects of a long DUP may also contribute to a favorable response following group $\mathrm{CBT}^{58}$

A recent study conducted in the U.S. revealed that the DUP influences the treatment response following comprehensive psychosocial services in patients with first-episode psychosis. ${ }^{42}$ In that study, participants with a median DUP of $\leq 74$ weeks showed greater improvements in quality of life and psychopathology compared with those with a longer DUP and those in community care. The authors proposed that reducing the DUP from its current level of approximately 1 year to a recommended standard of 3 months should be a major focus of applied research efforts. ${ }^{59-61}$ Patient outcomes are significantly worse when the DUP exceeds 3 months. ${ }^{4,62}$ The present findings indicated that a DUP shorter than 4 months may be critical to achieve a good response to psychosocial interventions in Korean patients with early psychosis.

There were significant improvements in the score on the hostility subscale of the AIHQ in both the short and long DUP groups. A perceived hostility bias may play a pivotal role in the paranoia associated with the first psychotic episode of schizophrenia and/or its prodromal phase, and this bias has been linked to a high paranoia score. ${ }^{43}$ The findings of the present study are compatible with those of previous studies that showed improvements in positive psychotic symptoms following MCT and individual CBT. ${ }^{23}$ Although the AIHQ is a self-report questionnaire, the score on the hostility subscale is rated by clinicians based on the attributional style of patients who respond to the questionnaire. The present study also demonstrated significant improvements in general clinical impression, as rated by clinicians, of patients regardless of the DUP. This is in line with a recent study that found the DUP does not influence the effects of MCT on schizophrenia symptoms. ${ }^{45}$ However, the group CBT procedure used in the present study, which included MCT, improved subjective well-being, attitude toward treatment, and depression more effectively in patients with a short DUP than in those with a long DUP. A previous study found that a longer DUP and a poorer level of insight predicted poor adherence to CBT, but this study did not investigate changes in therapeutic outcomes according to the DUP. ${ }^{57}$ In the present study, no differences in adherence to group CBT according to the DUP were detected, but scores on the DAI, which represent one's attitude toward treatment, were signifi- 
cantly improved in the short DUP group.

The SWN-K and DAI have been widely used to measure subjective responses to and attitudes about pharmacological treatments, and the importance of subjective measures has been repeatedly addressed in recent studies on schizophrenia. ${ }^{63,64}$ Subjective well-being is highly and positively correlated with quality of life, ${ }^{65,66}$ and it has been increasingly addressed in studies assessing the clinical courses and outcomes of patients with schizophrenia. ${ }^{67-70}$ In the present study, the effect size for the improvement in the total SWN-K score was moderate, and the mental functioning and social integration scores significantly improved with medium to large effect sizes in the short DUP group. Improvement in social integration is one of the most important treatment goals for patients with schizophrenia. ${ }^{71}$ Group interactions and activities as well as content of the CBT modules that were intended to enhance self-esteem, and the use of coping strategies, might have contributed to these improvements. It is interesting that the attitude toward medication significantly improved in the present study, even though the group CBT program did not include formal psychoeducation. However, the therapeutic relationship with one's case manager and peer sharing about one's treatment experience might have contributed to this.

The present study has several limitations that should be noted. First, the sample size was relatively small. Second, this was a retrospective study and formal objective ratings of the patients' psychopathologies and functioning were not included. Third, assessments of neurocognitive and intellectual functioning, which may be associated with the DUP and the ability to engage during CBT, were not performed. Fourth, the effects of other treatment factors were not controlled because this study had not control group. Finally, while the mean age of the subjects in this study was in the early twenties, most patients were not seen at their first episode. Therefore, a prospective controlled study is warranted, mainly focusing on the first episode or ultra-high risk stage in the Korean population.

In conclusion, the group CBT program used in the present study had a positive effect on subjective well-being, attitude toward treatment, perceived stress, and suspiciousness of young Asian patients with early psychosis. These effects were more pronounced in those with a shorter DUP, suggesting that the receipt of appropriate treatment at the proper time during the course of one's psychotic illness can have a substantial impact on outcome. The present study provides additional support for early identification of psychosis and intervention methods that can improve its course.

\section{Acknowledgments}

This study was supported by grants of the Korean Mental Health Technology R\&D Project, Ministry of Health \& Welfare, Republic of Korea (HM15C1140 and A120051). This research work was conducted as part of the Gwangju Mental Health Demonstration Project supported by Ministry of Health \& Welfare and Gwangju Metropolitan city, Republic of Korea. We thank Jae-Kyeong Kim and Jin-Hee Hong for their assistance in subject recruitment.

\section{REFERENCES}

1. McGorry PD, Killackey E, Yung AR. Early intervention in psychotic disorders: detection and treatment of the first episode and the critical early stages. Med J Aust 2007;187(7 Suppl):S8-S10.

2. McGorry PD, Killackey E, Yung A. Early intervention in psychosis: concepts, evidence and future directions. World Psychiatry 2008;7:148-156.

3. Perkins DO, Gu H, Boteva K, Lieberman JA. Relationship between duration of untreated psychosis and outcome in first-episode schizophrenia: a critical review and meta-analysis. Am J Psychiatry 2005;162:17851804.

4. Harris MG, Henry LP, Harrigan SM, Purcell R, Schwartz OS, Farrelly $\mathrm{SE}$, et al. The relationship between duration of untreated psychosis and outcome: an eight-year prospective study. Schizophr Res 2005;79:85-93.

5. Marshall M, Lewis S, Lockwood A, Drake R, Jones P, Croudace T. Association between duration of untreated psychosis and outcome in cohorts of first-episode patients: a systematic review. Arch Gen Psychiatry 2005;62:975-983.

6. Norman RM, Lewis SW, Marshall M. Duration of untreated psychosis and its relationship to clinical outcome. Br J Psychiatry Suppl 2005;48: S19-S23.

7. Chang WC, Hui CL, Tang JY, Wong GH, Chan SK, Lee EH, et al. Impacts of duration of untreated psychosis on cognition and negative symptoms in first-episode schizophrenia: a 3-year prospective follow-up study. Psychol Med 2013;43:1883-1893.

8. Tang JY, Chang WC, Hui CL, Wong GH, Chan SK, Lee EH, et al. Prospective relationship between duration of untreated psychosis and 13year clinical outcome: a first-episode psychosis study. Schizophr Res 2014;153:1-8.

9. Compton MT, Chien VH, Leiner AS, Goulding SM, Weiss PS. Mode of onset of psychosis and family involvement in help-seeking as determinants of duration of untreated psychosis. Soc Psychiatry Psychiatr Epidemiol 2008;43:975-982.

10. Birchwood M, Todd P, Jackson C. Early intervention in psychosis. The critical period hypothesis. Br J Psychiatry Suppl 1998;172:53-59.

11. McGorry PD. The recognition and optimal management of early psychosis: an evidence-based reform. World Psychiatry 2002;1:76-83.

12. National Institute for Health and Care Excellence. Psychosis and schizophrenia in adults: prevention and management (Clinical guideline 178). Available: http://guidance.nice.org.uk/CG178. Accessed Feb, 2014.

13. Tarrier N, Haddock G, Barrowclough C, Wykes T. Are all psychological treatments for psychosis equal? The need for CBT in the treatment of psychosis and not for psychodynamic psychotherapy. Psychol Psychother 2002;75:365-374.

14. Tarrier N, Lewis S, Haddock G, Bentall R, Drake R, Kindrman P, et al. Cognitive-behavioural therapy in first-episode and early schizophrenia. 18-month follow-up of a randomised controlled trial. Br J Psychiatry 2004;184:231-239.

15. Zimmermann G, Favrod J, Trieu VH, Pomini V. The effect of cognitive behavioral treatment on the positive symptoms of schizophrenia spectrum disorders: a meta-analysis. Schizophr Res 2005;77:1-9.

16. Wykes T, Steel C, Everitt B, Tarrier N. Cognitive behavior therapy for schizophrenia: effect sizes, clinical models, and methodological rigor. Schizophr Bull 2008;34:523-537.

17. Mueser KT, Deavers F, Penn DL, Cassisi JE. Psychosocial treatments for schizophrenia. Annu Rev Clin Psychol 2013;9:465-497.

18. Lecomte T, Leclerc C, Corbière M, Wykes T, Wallace CJ, Spidel A. Group cognitive behavior therapy or social skills training for individuals with a recent onset of psychosis? Results of a randomized controlled trial. J Nerv Ment Dis 2008;196:866-875. 
19. Lecomte T, Leclerc C, Wykes T. Group CBT for early psychosis--are there still benefits one year later? Int J Group Psychother 2012;62:309321.

20. Chung YC, Yoon KS, Park TW, Yang JC, Oh KY. Group cognitive-behavioral therapy for early psychosis. Cognit Ther Res 2013;37:403-411.

21. Moritz S, Vitzthum F, Randjbar S, Veckenstedt R, Woodward TS. Detecting and defusing cognitive traps: metacognitive intervention in schizophrenia. Curr Opin Psychiatry 2010;23:561-569.

22. Vitzthum FB, Veckenstedt R, Moritz S. Individualized metacognitive therapy program for patients with psychosis (MCT+): introduction of a novel approach for psychotic symptoms. Behav Cogn Psychother 2014;42:105-110.

23. Moritz S, Veckenstedt R, Bohn F, Hottenrott B, Scheu F, Randjbar S. Complementary group Metacognitive Training (MCT) reduces delusional ideation in schizophrenia. Schizophr Res 2013;151:61-69.

24. Moritz S, Veckenstedt R, Andreou C, Bohn F, Hottenrott B, Leighton L, et al. Sustained and "sleeper" effects of group metacognitive training for schizophrenia: a randomized clinical trial. JAMA Psychiatry 2014;71: 1103-1111.

25. Beck AT, Rector NA. Cognitive approaches to schizophrenia: theory and therapy. Annu Rev Clin Psychol 2005;1:577-606.

26. Yoo T, Kim SW, Kim SY, Lee JY, Kang HJ, Bae KY, et al. Relationship between Suicidality and Low Self-esteem in Patients with Schizophrenia. Clin Psychopharmacol Neurosci 2015;13:296-301.

27. Kim SW, Lee GY, Yu HY, Jung EI, Lee JY, Kim SY, et al. Development and feasibility of smartphone application for cognitive behavioral case management of individuals with early psychosis. Early Interv Psychiatry 2016 In press [Epub ahead of print].

28. Lee GY, Yu HY, Jhon M, Yoon JS, Kim SW. Intensive cognitive behavioral case management for functional recovery of young patients with schizophrenia. Korean J Schizophr Res 2016;19:32-37.

29. American Psychiatric Association. Diagnostic and statistical manual of mental disorders (5th Ed). Arlington, VA: American Psychiatric Publishing; 2013.

30. Naber D, Mortiz S, Lambert M, Pajonk FG, Holzbach R, Mass R, et al. Improvement of schizophrenic patients' subjective well-being under atypical antipsychotic drugs. Schizophr Res 2001;50:79-88.

31. Kim SW, Shin IS, Kim JM, Yoo JA, Ahn YM, Kwon JS, et al. A validation study of the Korean version of Subjective Well-being under Neuroleptic Treatment Scale-short form. Korean J Psychopharmacol 2007;18: 221-230.

32. Combs DR, Penn DL, Wicher M, Waldheter E. The Ambiguous Intentions Hostility Questionnaire (AIHQ): a new measure for evaluating hostile social-cognitive biases in paranoia. Cogn Neuropsychiatry 2007; 12:128-143.

33. Chang H, Lee SK, Kim KR, Lee SY, Park JY, Kim EJ, et al. Development of Korean version of the Ambiguous Intentions Hostility Questionnaire (K-AIHQ). J Korean Neuropsychiatr Assoc 2009;48:29-35.

34. Hogan TP, Awad AG, Eastwood R. A self-report scale predictive of drug compliance in schizophrenics: reliability and discriminative validity. Psychol Med 1983;13:177-183.

35. Yoon BH, Bahk WM, Lee KU, Hong CH, Ahn JK, Kim MK. Psychometric properties of Korean version of Drug Attitude Inventory (KDAI10). Korean J Psychopharmacol 2005;16:480-487.

36. Beck AT, Ward CH, Mendelson M, Mock J, Erbaugh J. An inventory for measuring depression. Arch Gen Psychiatry 1961;4:561-571.

37. Hahn HM, Yum TH, Shin YW, Kim KH, Yoon DJ, Chung KJ. Standardization study of Beck Depression Inventory in Korea. J Korean Neuropsychiatr Assoc 1986;25:487-502.

38. Cohen S, Williams G. Perceived Stress in a Probability Sample of the United States. Spacapan S, Oskamp S, Editors. The Social Psychology of Health: Thousand Oaks, CA, US: Sage Publications, Inc, 1988, p.31-67.

39. Lee J, Shin C, Ko YH, Lim JH, Joe SH, Kim SH, et al. The reliability and validity studies of the Korean version of the Perceived Stress Scale. Korean J Psychosom Med 2012;20:127-134.
40. Guy W. CGI Clinical Global Impressions. In ECDEU Assessment Manual for Psychopharmacology, Revised. Rockville MD: US Department of Mental Health, Education and Welfare, Public Health Service, Alcohol, Drug Abuse, and Mental Health Administration, 1976, p.217-222.

41. An SK, Kang JI, Park JY, Kim KR, Lee SY, Lee E. Attribution bias in ultra-high risk for psychosis and first-episode schizophrenia. Schizophr Res 2010;118:54-61

42. Combs DR, Penn DL, Michael CO, Basso MR, Weideman R, Siebenmorgan M, et al. Perceptions of hostility with and without persecutory delusions. Cogn Neuropsychiatry 2009;14:30-52.

43. Kane JM, Robinson DG, Schooler NR, Mueser KT, Penn DL, Rosenheck RA, et al. Comprehensive versus usual community care for firstepisode psychosis: 2-year outcomes from the NIMH RAISE early treatment program. Am J Psychiatry 2016;173:362-372.

44. Cohen J. Statistical Power Analysis for the Behavioral Sciences (2nd Ed). Hillsdale, NJ: Lawrence Earlbaum Associates; 1988.

45. Ussorio D, Giusti L, Wittekind CE, Bianchini V, Malavolta M, Pollice R, et al. Metacognitive training for young subjects (MCT young version) in the early stages of psychosis: is the duration of untreated psychosis a limiting factor? Psychol Psychother 2016;89:50-65.

46. Naeem F, Kingdon D, Turkington D. Predictors of response to cognitive behavior therapy in the treatment of schizophrenia: a comparison of brief and standard interventions. Cognit Ther Res 2008;32:651-656.

47. Brabban A, Tai S, Turkington D. Predictors of outcome in brief cognitive behavior therapy for schizophrenia. Schizophr Bull 2009;35:859-864.

48. Garety P, Fowler D, Kuipers E, Freeman D, Dunn G, Bebbington P, et al. London-East Anglia randomised controlled trial of cognitive-behaviour therapy for psychosis. II: Predictors of outcome. Br J Psychiatry 1997;171:420-426.

49. Menon M, Andersen DR, Quilty LC, Woodward TS. Individual factors predicted to influence outcome in group CBT for psychosis (CBTp) and related therapies. Front Psychol 2015;6:1563.

50. Beauchamp MC, Lecomte T, Lecomte C, Leclerc C, Corbière M. Do personality traits matter when choosing a group therapy for early psychosis? Psychol Psychother 2013;86:19-32.

51. Uçok A, Polat A, Genç A, Cakir S, Turan N. Duration of untreated psychosis may predict acute treatment response in first-episode schizophrenia. J Psychiatr Res 2004;38:163-168.

52. Perkins D, Lieberman J, Gu H, Tohen M, McEvoy J, Green A, et al. Predictors of antipsychotic treatment response in patients with first-episode schizophrenia, schizoaffective and schizophreniform disorders. Br J Psychiatry 2004;185:18-24.

53. Rangaswamy T, Mangala R, Mohan G, Joseph J, John S. Intervention for first episode psychosis in India-The SCARF experience. Asian J Psychiatr 2012;5:58-62.

54. Marshall M, Husain N, Bork N, Chaudhry IB, Lester H, Everard L, et al. Impact of early intervention services on duration of untreated psychosis: data from the National EDEN prospective cohort study. Schizophr Res 2014;159:1-6.

55. Penttilä M, Jääskeläinen E, Hirvonen N, Isohanni M, Miettunen J. Duration of untreated psychosis as predictor of long-term outcome in schizophrenia: systematic review and meta-analysis. Br J Psychiatry 2014;205: 88-94.

56. Lappin JM, Morgan KD, Morgan C, Dazzan P, Reichenberg A, Zanelli JW, et al. Duration of untreated psychosis and neuropsychological function in first episode psychosis. Schizophr Res 2007;95:103-110.

57. Malla AK, Norman RM, Manchanda R, Townsend L. Symptoms, cognition, treatment adherence and functional outcome in first-episode psychosis. Psychol Med 2002;32:1109-1119.

58. Alvarez-Jiménez M, Gleeson JF, Cotton S, Wade D, Gee D, Pearce T, et al. Predictors of adherence to cognitive-behavioural therapy in first-episode psychosis. Can J Psychiatry 2009;54:710-718.

59. Addington J, Heinssen RK, Robinson DG, Schooler NR, Marcy P, Brunette MF, et al. Duration of Untreated Psychosis in Community Treatment Settings in the United States. Psychiatr Serv 2015;66:753-756. 
60. Alvarez-Jimenez M, Gleeson JF, Henry LP, Harrigan SM, Harris MG, Amminger GP, et al. Prediction of a single psychotic episode: a 7.5-year, prospective study in first-episode psychosis. Schizophr Res 2011;125: 236-246.

61. Bertolote J, McGorry P. Early intervention and recovery for young people with early psychosis: consensus statement. Br J Psychiatry Suppl 2005;48:S116-S119.

62. Schimmelmann BG, Huber CG, Lambert M, Cotton S, McGorry PD, Conus P. Impact of duration of untreated psychosis on pre-treatment, baseline, and outcome characteristics in an epidemiological first-episode psychosis cohort. J Psychiatr Res 2008;42:982-990.

63. Moritz S, Krausz M, Gottwalz E, Lambert M, Perro C, Ganzer S, et al. Cognitive dysfunction at baseline predicts symptomatic 1-year outcome in first-episode schizophrenics. Psychopathology 2000;33:48-51.

64. Naber D. A self-rating to measure subjective effects of neuroleptic drug relationships to objective psychopathology, quality of life, compliance, and other clinical variables. Int Clin Psychopharmacol 1995;10(Suppl 3): 133-138.

65. Karow A, Moritz S, Lambert M, Schoder S, Krausz M. PANSS syndromes and quality of life in schizophrenia. Psychopathology 2005;38: 320-326.

66. Wehmeier PM, Kluge M, Schneider E, Schacht A, Wagner T, Schreiber W. Quality of life and subjective well-being during treatment with an- tipsychotics in out-patients with schizophrenia. Prog Neuropsychopharmacol Biol Psychiatry 2007;30:703-712.

67. Jones PB, Barnes TR, Davies L, Dunn G, Lloyd H, Hayhurst KP, et al. Randomized controlled trial of the effect on quality of life of secondversus first-generation antipsychotic drugs in schizophrenia: Cost Utility of the Latest Antipsychotic Drugs in Schizophrenia Study (CUtLASS 1). Arch Gen Psychiatry 2006;63:1079-1087.

68. Lambert M, Naber D, Eich FX, Schacht M, Linden M, Schimmelmann BG. Remission of severely impaired subjective well-being in 727 patients with schizophrenia treated with amisulpride. Acta Psychiatr Scand 2007;115:106-113.

69. Kim SW, Yoon JS, Kim YS, Ahn YM, Kim CE, Go HJ, et al. The effect of paliperidone extended release on subjective well-being and responses in patients with schizophrenia. Prog Neuropsychopharmacol Biol Psychiatry 2012;38:228-235.

70. Karow A, Naber D, Lambert M, Moritz S; EGOFORS Initiative. Remission as perceived by people with schizophrenia, family members and psychiatrists. Eur Psychiatry 2012;27:426-431.

71. Rossi A, Vita A, Tiradritti P, Romeo F. Assessment of clinical and metabolic status, and subjective well-being, in schizophrenic patients switched from typical and atypical antipsychotics to ziprasidone. Int Clin Psychopharmacol 2008;23:216-222. 